\title{
Quantitative phosphoproteomic analysis of the tumor necrosis factor pathway
}

\author{
Greg T. Cantin, John D. Venable, Daniel Cociorva, and John R. Yates III \\ Department of Cell Biology, The Scripps Research Institute, 10550 North Torrey Pines Rd. SR11, \\ La Jolla, CA 92037, USA
}

\begin{abstract}
Protein phosphorylation has become a focus of many proteomic studies due to the central role that it plays in biology. We combine peptide-based gel-free isoelectric focusing and immobilized metal affinity chromatography to enhance the detection of phosphorylation events within complex protein samples using LC-MS. This method is then used to carry out a quantitative phosphoproteomic analysis of the tumor necrosis factor (TNF) pathway using HeLa cells metabolically labeled with ${ }^{15} \mathrm{~N}$-containing amino acids, where 145 phosphorylation sites were found to be up-regulated upon the activation of the TNF pathway.
\end{abstract}

\section{Keywords}

Isoelectric focusing; IMAC; phosphoproteome; metabolic labeling; TNF; PKA; apoptosis

\section{Introduction}

Protein phosphorylation has been shown to be an important post-translational modification, regulating activities as diverse as protein-protein interactions, enzymatic activity, subcellular localization, and ubiquitin-mediated degradation ${ }^{1}$. Due to the wide spectrum of changes that phosphorylation can impart to a protein, it is no surprise that this post-translational modification has been implicated in numerous biological processes. On a larger scale, changes in the phosphorylation of specific proteins have been implicated in a variety of human diseases; and because of this, there is an enormous amount of interest in the development of methods to identify protein phosphorylation on a global scale in the hope of unveiling phosphorylation events that are specific to a disease state. Identifying such events will be critical in understanding many different diseases and pivotal in determining therapeutic targets for future drug development.

Identifying protein phosphorylation, however, has proven to be a formidable challenge. In the past, a variety of techniques, primarily involving biochemical and molecular biology tools, have been used to analyze protein phosphorylation. In typical studies, these methods can only practically be applied to a few proteins at a time; resulting in a slow progress in identifying new phosphorylation sites. However, the use of mass spectrometry in the analysis of protein phosphorylation has dramatically sped up the process; and because of this, a variety of mass spectrometry platforms are currently being used to study phosphorylation. Within the past few years, tandem mass spectrometers have dominated these analyses because collected tandem mass spectra can be used to not only identify phosphorylated peptides and assign them to a

\footnotetext{
*To whom correspondence should be addressed. E-mail: jyates@ scripps.edu. Tel: 858-784-8862. Fax: 858-784-8883.
} 
specific protein, but, in many cases, also localize the site of phosphorylation to a particular amino acid $^{2-6}$.

It has been estimated that as many as $30 \%$ of mammalian proteins are phosphorylated. Even though a large percentage of proteins may be phosphorylated in mammalian cells, a large dynamic range in protein concentration results in some phosphoproteins being present at concentrations orders of magnitude lower than others. This issue is the biggest obstacle faced in attempts to carry out a complete phosphoproteomic analysis by mass spectrometry. Additionally, phosphorylation of a particular site in vivo is often substoichiometric ${ }^{7}$ making the aforementioned problem even more difficult. Due to this, it is generally agreed upon that some type of enrichment scheme which can target phosphoproteins and/or phosphopeptides (reducing the complexity of the sample to be analyzed by mass spectrometry) is needed in order for a complete phosphoproteomic analysis of a complex protein mixture to be carried out.

If tandem mass spectrometry is to be used for an analysis, another challenge lies in the inherent difficulty in identifying phosphopeptides compared to unmodified peptides. This difficulty is due to multiple factors including: 1.) the highly negative charge of a phosphopeptide results in suppression of ionization when using the positive ion mode of detection 8 (which is typically used in MS/MS analysis of peptides), and 2.) MS/MS spectra from phosphoserine and phosphothreonine-containing peptides are often of poor quality due to the dominant loss of phosphoric acid and reduced amount of informative cleavage across the peptide backbone 9 . As a result, some laboratories have developed and/or utilized mass spectrometry-specific methods to address these issues in phosphopeptide analysis $2,5-7,10$.

A number of phosphoprotein/phosphopeptide enrichment strategies coupled to mass spectrometry have been developed over the last few years, most of which have been previously reviewed $^{3}, 8,11,12$. However, no method has matured and become robust enough to be considered the method of choice. Thus, at this point, phosphoproteomic method development is still needed. In this study, we analyze the effects of fractionating a digested mammalian whole cell extract via isoelectric focusing (IEF) prior to LC-MS analysis. We demonstrate that this pI-based fractionation allows for a moderate enrichment of phosphopeptides in the low $\mathrm{pH}$ fractions. We then combine this fractionation procedure with immobilized metal affinity chromatography (IMAC) to generate a highly enriched pool of phosphopeptides that is subsequently analyzed by an LC-MS/MS/MS strategy previously shown to enhance the detection of phosphoserine and phosphothreonine-containing peptides 5,6 . This combined approach is used to quantitatively analyze phosphorylation events specific to the tumor necrosis factor (TNF) signal transduction pathway using HeLa cells metabolically labeled with ${ }^{15} \mathrm{~N}-$ containing amino acids. This pathway was chosen for two reasons: first, because phosphorylation is known to play a key role in the transduction of the TNF signal through multiple protein components; and second, because the pathway is of great interest to many researchers due to its integral role in inflammation, apoptosis, and cancer ${ }^{13-15}$. From a combined quantitative and qualitative analysis, $\sim 700$ phosphopeptides were identified, where 106 phosphopeptides and 145 phosphorylation sites were found to be up-regulated by TNF; these consisted of sites previously known to be regulated by TNF, known sites with unknown modes of regulation, and entirely novel phosphorylation sites.

\section{Experimental Section}

\section{Procedures. 1. Cell Culture and Protein Extraction}

HeLa-S3 cells purchased from National Cell Culture Center were used in the initial IEF experiments. Whole cell protein extract was prepared with Trizol reagent (Invitrogen) as directed by the manufacturer. For the analysis of untreated and TNF-treated cells, adherent 
HeLa cells were grown in "Homemade" DMEM media and is fully detailed in Supplementary Methods, and is similar to the published recipe for 10-013 DMEM from Mediatech, Inc. Briefly, culture media was made using dialyzed fetal bovine serum (Invitrogen, 26400) to 10\%, and either ${ }^{14} \mathrm{~N}$ or ${ }^{15} \mathrm{~N}$ amino acid mix (Spectra Stable Isotopes, 520000/532098) to $800 \mathrm{mg} / \mathrm{L}$. The percent isotope enrichment for the ${ }^{15} \mathrm{~N}$-labeled amino acid mix was $<98 \%$. For each culture, the adherent cells (grown in either four or five $15 \mathrm{~cm}$ plates) were washed with PBS and either left untreated or were treated with recombinant human tumor necrosis factor alpha (R\&D Systems, 210-TA) at 20ng/ml in PBS for seven minutes as previously

recommended ${ }^{16}$. Supernatant was then cleared and the cells were detached via Trypsin/EDTA solution (Cellgro, 25-053-C1) and scraping. The cell suspension was then spun at 2,200 $\mathrm{rcf}$ for two minutes, and the supernatant was decanted. Protein was then extracted from the cell pellet via Trizol reagent.

\section{Isoelectric Focusing of Protein Digest}

Precipitated protein from a Trizol extraction was resuspended in $8 \mathrm{M}$ urea $100 \mathrm{mM}$ Tris $\mathrm{pH} 8.5$ at $\sim 4.5 \mathrm{mg} / \mathrm{ml}$ (expected amount of protein was determined from previous experiments where $\sim 0.12 \mathrm{mg}$ of protein was extracted from $1 \times 10^{6} \mathrm{HeLa}$ cells using Trizol reagent) and incubated at $50^{\circ} \mathrm{C}$ for $30 \mathrm{~min}$. with intermittent vortexing in order to get the majority of the precipitate into solution. The protein mixture was then reduced by adding TCEP to $5 \mathrm{mM}$ and incubating for $30 \mathrm{~min}$. at room temperature (R.T.), followed by cysteine alkylation with iodoacetamide at $10 \mathrm{mM}$ and incubating in the dark for $30 \mathrm{~min}$. at R.T. The mixture was then diluted to $4 \mathrm{M}$ urea by adding an equivalent volume of $100 \mathrm{mM}$ Tris $\mathrm{pH} 8.5$, and $\mathrm{CaCl}_{2}$ was added to $2 \mathrm{mM}$. Trypsin (Promega, modified sequencing grade) was added at 1:500 (enzyme:substrate, wt/wt) and incubated at $37^{\circ} \mathrm{C}$ for $\sim 24 \mathrm{hr}$., then trypsin was added again at $\sim 1: 500$ and incubated for another $24 \mathrm{hr}$ at $37^{\circ} \mathrm{C}$. Approximate, but relative, protein concentration of each sample was determined after digestion using both the DC Protein Assay (Bio-Rad) and $\mathrm{A}_{280}$ readings. Each digest was then desalted by solid phase extraction on C18 (SPEC, Varian) according to manufacturers instruction and lyophilized by speed vac (Savant). The sample was then prepared for gel-free isoelectric focusing using the ZOOM ${ }^{\circledR}$ IEF Fractionator (Invitrogen). Buffers and reagents were prepared as described in Supporting Information. $2.5 \mathrm{mg}$ of the desalted digest was resuspended in $4.188 \mathrm{ml}$ of $1 \times$ ZOOM Fractionator sample buffer without CHAPS. A total of $2 \mathrm{mg}$ was loaded in the fractionator and run as described in Supporting Information, using ZOOM ${ }^{\circledR}$ Disks of $\mathrm{pH}$ 3.0, 4.6, 5.4, 6.2, 7.0, and 10.0. After running, each of the five fractions was named after the $\mathrm{pH}$ of the lower of the two disks flanking the fraction, and stored at $-80^{\circ}$ C. Prior to analysis by MudPIT, one fourth of each fraction was spun at $\sim 14,000 \mathrm{rcf}$ for $10 \mathrm{~min}$ to remove insoluble material. Formic acid was then added to the supernatant to a final concentration of $4 \%(\mathrm{v} / \mathrm{v})$ prior to column loading.

\section{Isoelectric Focusing of Intact Protein}

Precipitated protein from a Trizol extraction was resuspended in 1x ZOOM Fractionator sample buffer (containing CHAPS) to an estimated concentration of $4 \mathrm{mg} / \mathrm{ml}$, and heated to $50^{\circ} \mathrm{C}$ for 20 min., with intermittent vortexing. Protein was reduced with DTT and cysteines were alkylated with DMA (N,N-dimethylacrylamide, 99\%, Sigma) as described in Supporting Information, and $2 \mathrm{mg}$ was then run on the fractionator as above. One fourth of each fraction was separately subjected to acetone precipitation in order to remove CHAPS. The precipitated protein was resuspended in $100 \mu \mathrm{l}$ of $8 \mathrm{M}$ urea $100 \mathrm{mM}$ Tris $\mathrm{pH} 8.5$ and heated to $50^{\circ} \mathrm{C}$ for 30 min. with intermittent vortexing. The concentration of urea was reduced to $4 \mathrm{M}$ by the addition of an equal volume of $100 \mathrm{mM}$ Tris $\mathrm{pH} 8.5, \mathrm{CaCl}_{2}$ was added and the protein mixture was subjected to tryptic digestion as above. The digestions were stopped with the addition of formic acid to $4 \%$. 


\section{MudPIT Analysis}

One fourth of each processed fraction was separately loaded onto a 3-phase MudPIT column ${ }^{17}$ described in detail in Supplementary Methods. Subsequently, LC/LC-MS/MS was carried out (see Supplementary Methods) using an HP1100 HPLC (Hewlett Packard) online with an LCQ Deca ion trap mass spectrometer (Thermo Electron), and MS/MS spectra were collected as previously described ${ }^{18}$. MS/MS spectra were processed and searched against a human protein database differentially considering phosphorylation at serine and threonine using SEQUEST ${ }^{19}$ (further details in Supplementary Methods). All subsequent filtering and comparisons of identifications were made using DTASelect and Contrast software ${ }^{20}$. A description of the algorithm used to determine the $\mathrm{pI}$ of peptides can be found at the following link, http://fields.scripps.edu/DTASelect/20010710-pI-Algorithm.pdf.

\section{Phosphopeptide enrichment and analysis of +/- TNF-treated cells}

Protein was extracted from each ${ }^{14} \mathrm{~N}$ or ${ }^{15} \mathrm{~N}$-labeled culture and digested with trypsin as described above. Protein/peptide concentrations, after digestion, were initially determined by $\mathrm{A}_{280}$ readings. After determining the accurate relative concentrations of each digest (as described in Supplementary Methods), a 1:1 digest mixture (3.8 $\mathrm{mg}$ total) was made, subsequently desalted over C18, split into two aliquots and fractionated by two separate gelfree isoelectric focusing runs as described above. The " $\mathrm{pH} 3$ " fractions from each run were combined, as were the two "pH 4.6" fractions. To remove insoluble material, each fraction $(\sim 1150 \mu \mathrm{l})$ was filtered using $0.45 \mu \mathrm{m}$ Ultrafree-MC $0.5 \mathrm{ml}$ centrifugal filter devices (Millipore) and then split into eight aliquots. Each aliquot was subjected to IMAC using $25 \mu 1$ Gallium-Chelated resin in a mini-spin column as described by the manufacturer (Pierce, 89853) and further detailed in Supporting Information. All IMAC eluates were combined and split into three aliquots for analysis by LC-MS. Each aliquot was loaded onto $4 \mathrm{~cm}$ of $5 \mu \mathrm{m}$-sized C18 resin (Aqua, Phenomenex) packed in $100 \mu \mathrm{m}$ (i.d.) fused silica attached to a filter assembly, and then washed with buffer A for $5 \mathrm{~min}$. An $11 \mathrm{~cm} \mathrm{C18}$ analytical column ( $100 \mu \mathrm{m}$ (i.d.) with a tip laser-pulled to 5-15 $\mu \mathrm{m}$ ) was then attached to the assembly and run on an LTQ linear ion trap mass spectrometer (Thermo Electron) attached to an HP 1100 HPLC and developed using a reversed-phase gradient (see Supplementary Methods). The instrument method consisted of a full MS scan from $400-1400 \mathrm{~m} / \mathrm{z}$ followed by data-dependent MS/MS on the five most intense ions. Additionally, MS/MS/MS (MS3) was triggered for precursor ions undergoing a neutralloss of either 98,49 , or $32.7 \mathrm{~m} / \mathrm{z}$ upon MS/MS ${ }^{5}, 6$. AGC targets of 20,000 and 10,000 with 50 and $100 \mathrm{msec}$ max ion times were used for MS and MSn scans, respectively. The minimum signals required for MS/MS and MS3 were 1000 and 100, respectively; and an isolation width of $3 \mathrm{~m} / \mathrm{z}$ and normalized collision energy of $35 \%$ was used for both. RAW files were split into MS2 and MS3 files using the program Raw Extract (written by John Venable). MS2 files were filtered using the previously described program ${ }^{21}$, and MS3 files were left unfiltered. The MS2 and MS3 files were then separately subjected to SEQUEST searches. To construct the database used in these searches, the EBI-IPI human database (version 3.04 released 03-07-2005) was first attached to a list of frequently occurring contaminants (e.g. proteases and keratins), then this database was combined with its reversed version. The parameters of the searches were similar to those used above; however, for MS2 searches, tyrosine phosphorylation was now considered, and, additionally for MS3 searches, a loss of 18 Da was differentially searched for on serine and threonine, which is indicative of a neutral loss of phosphoric acid from a phosphoserine or phosphothreonine-containing peptide. Two separate searches for each MS data file were carried out, considering both ${ }^{14} \mathrm{~N}$ and ${ }^{15} \mathrm{~N}$-containing amino acids. In filtering the search results, a new feature was added to DTASelect that reports the DeltaCN of the first unrelated peptide in amino acid sequence, essentially ignoring peptides identical in sequence but modified at a different site when filtering based on the DeltaCN of each identification. This is done to allow for the identification of phosphopeptides where the exact location of the phosphorylation site(s) can not be conclusively determined by SEQUEST. This is a fairly 
common problem encountered in phosphopeptide analysis, and is due to instances where phosphopeptides containing closely-spaced serines and or threonines produce MS/MS spectra that are missing definitive fragment ions. The SEQUEST identifications were then filtered as described above with the additional removal of identifications from the reverse database. Ultimately, phosphopeptides with DeltaCN scores above 0.08 were determined to have the site (s) of phosphorylation localized, whereas those with scores below 0.08 are labeled as notlocalized and all of the probable sites are listed (using the $2^{\text {nd }}-5^{\text {th }}$ best scoring peptides within a DeltaCN score of 0.08). RelEx was then used to quantify relative abundances of the ${ }^{14} \mathrm{~N}$ and ${ }^{15} \mathrm{~N}$ versions of the identified phosphopeptides essentially as previously reported ${ }^{22}$, except that a precursor ion signal to noise filter of 2 was used, the correlation filter was dropped, and the atomic percent enrichment for the ${ }^{15} \mathrm{~N}$-containing samples were $90 \%$ (see Supplementary Methods).

\section{Results and Discussion}

\section{Phosphopeptide Enrichment from Digests of Whole Cell Protein using gel-free IEF}

Upon phosphorylation, peptides will generally shift from a higher to a lower pI due to the highly negative charge of the added phosphate moiety. Due to this property, we were able to generate fractions that are enriched in phosphopeptides by subjecting an extremely complex peptide mixture to gel-free IEF using the ZOOM IEF Fractionator (Invitrogen), which is modeled after a previously described device 23 . To generate the sample, a whole cell protein extract was prepared from HeLa cells using Trizol reagent, digested with trypsin, and subsequently desalted by solid phase extraction on C18. Approximately $2 \mathrm{mg}$ of the peptide mixture was then subjected to gel-free IEF, generating five fractions based on $\mathrm{pI}$ (see Experimental Section). One quarter of each fraction was then subjected to an LC/LC-MS/MS analysis termed MudPIT (multidimensional protein identification technology) (see Experimental Section). MS/MS spectra from this analysis were ultimately searched against a human database using the algorithm SEQUEST ${ }^{19}$, differentially considering serine and threonine to be phosphorylated.

To determine the effectiveness of the IEF fractionation, we first generated lists of the peptides identified in each IEF fraction by MudPIT. To do this, we used default cross correlation (XCorr) $(1.8,2.5$ and 3.5, for $+1,+2$, and +3 charged peptides, respectively) and $\Delta \mathrm{Cn}(0.08)$ cutoff values, and allowed only for the identification of fully tryptic unmodified peptides. Together, 5,242 unmodified peptides were identified (this is the non-redundant number, some peptides were identified in multiple $\mathrm{pH}$ fractions), corresponding to 1,934 proteins. In Figure 1 we show the average $\mathrm{pI}$ of the unmodified peptides that were identified in each IEF fraction; the $\mathrm{pI}$ of each peptide was determined as previously described (Experimental Section). These results demonstrate that a pI-based fractionation of peptides was effectively achieved. When considering the identification of phosphopeptides, the same filtering criteria as described above were used. Table 1 shows both the number of phosphopeptides and unmodified peptides identified in each fraction. We then compared the ratio of the number of phosphopeptides to the number of unmodified peptides found in each fraction. Displayed in Table 1 is the ratio for each IEF fraction, normalized to fraction "pH 3" (fractions are named after the lower of the two $\mathrm{pH}$ discs which flank each IEF fraction/chamber). It is apparent that this ratio generally decreases from fraction " $\mathrm{pH} 3$ " to fraction " $\mathrm{pH} 7$ ", suggesting that there is an enrichment of phosphopeptides occurring in the lower $\mathrm{pI}$ fractions. Additionally, this experiment was repeated two times producing similar results as those described above (data not shown). Lastly, the $\mathrm{pI}$ of the identified phosphopeptides were determined using the web-based program ProMoST ${ }^{24}$. Similar to the analysis of unmodified peptides, the pI of the phosphopeptides also correlate with the $\mathrm{pH}$ fraction that they were identified in (data not shown). 


\section{IEF of Intact Protein}

We were also interested in pre-fractionating intact proteins via IEF and determining how this would compare to the above method in regards to identifying phosphorylation sites. To do this, whole cell extract was prepared as above, using Trizol reagent, and the protein precipitate was then resolubilized and subjected to IEF fractionation as described in the Experimental Section. One fourth of each IEF fraction was precipitated by acetone, in order to remove detergent, digested with trypsin, and then subjected to the same MudPIT analysis as above. Table 2 shows the number of proteins, unmodified peptides and phosphopeptides identified in each IEF fraction. From this analysis it can be seen that there is no particular enrichment of identified phosphopeptides in any of the fractions. This shows that phosphoproteins within a complex protein mixture can not be enriched by IEF, as opposed to what was seen for phosphopeptides within a complex peptide mixture. This is not surprising, since it is expected that phosphorylation will generally have more of an effect in reducing the $\mathrm{pI}$ of a typical tryptic peptide than of a full length protein due to the large difference in amino acid sequence length between the two.

\section{Quantitative Phosphoproteomic Analysis of the Tumor Necrosis Factor Pathway}

Due to the inability of peptide-based IEF to produce a satisfactory pool of phosphopeptides, we decided to try using IMAC downstream of this separation procedure in order to enhance the enrichment of phosphopeptides from a complex protein digest. To do this, different amounts of each IEF fraction was subjected to IMAC and subsequently analyzed by LC-MS. Based on the number of phosphopeptides and unmodified peptides identified in trial runs (data not shown), it was decided that only the two lowest pI fractions ("pH 3" and "pH 4.6") would be subjected to IMAC in future analyses. These two fractions produced the highest number of identified phosphopeptides in the IMAC eluates and also the best ratios of phosphopeptides to unmodified peptides (data not shown).

To demonstrate the effectiveness of combining peptide-based IEF and IMAC, we carried out a quantitative analysis of the phosphorylation events that are induced by the activation of the TNF receptor in HeLa cells. Adherent HeLa cells were grown in media with either ${ }^{14} \mathrm{~N}$ or ${ }^{15} \mathrm{~N}$-labeled amino acids, where the ${ }^{14} \mathrm{~N}$ culture was stimulated with TNF- $\alpha$ for $\sim 7$ minutes and the other left untreated. Subsequently, a whole cell protein extract was prepared and digested with trypsin as previously described. A 1:1 mixture of each digest was made (see Experimental Section) and then fractionated by IEF as previously described. The two lowest pI fractions were then separately subjected to IMAC, subsequently pooled, and then analyzed by LC-MS/MS/MS using a linear ion trap mass spectrometer (LTQ, Thermo Electron) in triplicate; where, in addition to data-dependent MS/MS, a data-dependent MS/MS/MS scan was carried out upon the observation of a neutral loss of phosphoric acid from the precursor ion in the MS/MS spectra. This neutral loss is common during CID of phosphoserine and phosphothreonine-containing peptides, due to the labile nature of the phosphate bond; where the neutral loss ion often dominates the MS/MS spectra, resulting in poor quality and difficult to identify spectra ${ }^{9}$. Essentially, the aforementioned MS/MS/MS strategy is designed to increase the number of phosphoserine and phosphothreonine containing peptides identified, and has previously been shown to be a successful strategy 5,6 . Resulting spectra were searched against a combined forward and reversed human protein database (IPI) using SEQUEST; MS/ MS and MS/MS/MS were separately searched as describe in the Experimental Section resulting in the identification of phosphoserine, phosphothreonine, and phosphotyrosine-containing peptides from both the ${ }^{14} \mathrm{~N}$ and ${ }^{15} \mathrm{~N}$ sample. In total 701 phosphopeptides were identified between the three replicates.

The software program RelEx ${ }^{22}$ was then used to quantify the relative amounts of the ${ }^{14} \mathrm{~N}$ and ${ }^{15} \mathrm{~N}$-containing phosphopeptides identified in the above analysis. Utilizing identifications 
from both MS/MS and MS/MS/MS spectra, RelEx was used to automatically determine the relative abundance ratio of the precursor ion peaks for the corresponding ${ }^{15} \mathrm{~N}$ and ${ }^{14} \mathrm{~N}$ containing phosphopeptides. Due to stringent filtering ${ }^{22}$, a large number of identifications could not be automatically quantified by RelEx and were thus discarded in the quantitative analysis. Ultimately, 223 phosphopeptides passed the quantitative filtering criteria. Of these, 33 phosphopeptides (containing 56 phosphorylation sites) were found to be up-regulated by 2 -fold or more and 15 phosphopeptides (containing 23 sites) were found to be down-regulated by 2 -fold or more due to treatment with TNF- $\alpha$. In previous studies, 2 -fold changes have been shown to be biologically significant ${ }^{6}$. Within the up-regulated group, some of the phosphorylation sites have been previously found to be induced upon activation of the TNF receptor (see below) or due to the activation of a known component of the TNF signaling pathway (see below), indicating that the combined method is capable of finding and quantifying differences in phosphorylation events induced upon the activation of a signal transduction cascade in mammalian cells.

The reciprocal labeling experiment was also carried out, where the above experiment was essentially repeated except that the cells grown in ${ }^{14} \mathrm{~N}$-containing media were left untreated and those grown in ${ }^{15} \mathrm{~N}$-containing media were stimulated with TNF- $\alpha$. This type of reciprocal labeling experiment was performed in an attempt to confirm the first set of quantitative measurements by observing the reciprocal measurements when the labeling of the samples is reversed. Such confirmation also helps eliminate the possibility of a biological isotope effect. In relation to this experiment, it would eliminate the possibility that the observed quantitative differences between the samples were due to biological changes induced by differences in the nitrogen content of the medias, adding confidence to the notion that all differences observed are the result of the activation of the TNF pathway. When comparing the two reciprocal labeling experiments, it was found that many of the same phosphopeptides were quantified in both experiments (Supporting Information); however, none of the up or down regulated phosphopeptides were quantified in the reciprocal labeling experiment. A number of reasons could explain these results, some of which could include: 1 .) a reduction in the ability to identify incomplete ${ }^{15} \mathrm{~N}$-labeled peptides via SEQUEST; 2.) variation in sample processing; or 3.) experimental biological variation. A complete listing of results from the quantitative analyses can be found in Supporting Information.

As previously mentioned, a large number of identified phosphopeptides could not be used in the above quantitative analysis of the TNF pathway. The explanation lies in the fact that tandem MS can be acquired from precursor ion signals with low signal-tonoise, where an identification can be made eventhough the precursor ion peak can not be quantified. However, we felt that biologically useful information could still be extracted from this identification data. We thus decided to carry out a qualitative comparison of the phosphopeptides identified in the above experiments in an attempt to uncover additional phosphorylation events that are specific to the TNF pathway. To do this, we compared the phosphopeptides identified in the ${ }^{14} \mathrm{~N}$-TNF-treated sample to the combined identifications of the ${ }^{14} \mathrm{~N}$-untreated and the ${ }^{15} \mathrm{~N}$-untreated samples. From this comparison, a list was made consisting of phosphopeptides that were found in at least two replicates from the ${ }^{14} \mathrm{~N}-\mathrm{TNF}$-treated sample and not found in any of the replicates from the untreated samples. Additionally, phosphopeptides with the same sequence but differing in the site of phosphorylation were considered the same peptide, preventing such phosphopeptides from making it on this list. Ultimately, 79 phosphopeptides containing a total of 97 phosphorylation sites met the above criteria and will subsequently be deemed TNFregulated (Supporting Information).

The phosphorylation sites determined to be differentially regulated in both the quantitative and qualitative analysis were further scrutinized with the aid of two public databases:

PhosphoSite ${ }^{\mathrm{TM}}$ (http://www.phosphosite.org) and Swiss-Prot (http://us.expasy.org/sprot). We 
will only focus on the phosphorylation events found to be upregulated by TNF treatment for the remainder of the discussion. Although the sites that were found to be phosphorylated only in the untreated cells will not be discussed, these may represent sites of dephosphorylation that are specific to the TNF pathway, and thus are also worthy of further analysis.

Within the aforementioned lists of TNF-regulated phosphorylation events, the majority of the sites identified are novel. Of those previously identified, a significant majority have only been identified in a biologically 'non-specific' phosphoproteomic study 5 ; and thus the mode of regulation, if any, is unknown. However, some of the phosphorylation sites identified here have been previously shown to be regulated by kinases that are activated during the stimulation of the TNF pathway, and the corresponding proteins are illustrated in Fig. 2; additionally, these sites of phosphorylation along with additional quantitative and qualitative data on the identified phosphopeptides are listed in Table 3. Interestingly, a phosphorylation site was found on PKA catalytic subunit $\alpha$ (PKA-c- $\alpha$ ) that has previously been shown to activate its kinase activity ${ }^{25}$. Related to the activation of PKA, a number of known PKA-dependent phosphorylation sites were found to be upregulated upon TNF- $\alpha$ treatment; this includes Hsp$\beta-126$, annexin $1^{27}$, and possibly PMCA1 (a site was found 20 a.a. away from a known site $^{28}$ ), which is illustrated in Fig. 2. Most importantly, PKA has been shown to be activated during highly related signaling events initiated by the ligands IL-1 and LPS that lead to the direct phosphorylation of NF-KB by PKA ${ }^{29}$. Since IL-1 and LPS mediated activation of NF$\kappa \mathrm{B}$ share many of the same signaling components that are utilized in the TNF- $\alpha$ cascade ${ }^{30}$, it is not surprising to uncover these PKA-specific phosphorylation events as being regulated by TNF- $\alpha$ in this study. Also, there were additional TNF-regulated phosphorylation sites found on leukosialin and filamin A, both of which have been shown to be phosphorylated by other kinases known to be activated by TNF- $\alpha 31,32$. Some of these proteins (i.e. PKA, filamin A, and Hsp- $\beta-1$ ) are also known to have certain properties or functions related to the TNF pathway, and these functions are further detailed in Fig. 2. However, in only one of these three proteins is it known what the functional consequence is of the identified phosphorylation event; in this case, for PKA, the consequence is in the activation of its kinase-activity resulting in the phosphorylation and activation of NF- $\mathrm{KB}^{29}$ including other factors in the pathway. However, the effect of the phosphorylations on Hsp- $\beta-1$ and filamin A are not known. Altogether, the aforementioned phosphorylation events depicted in Fig. 2 demonstrate that many of the TNFregulated sites identified in this study are bona fide TNF-regulated events, indicating that the analysis as a whole was successful in its aim and, thus, should lend confidence to the other phosphorylation sites that are also determined to be TNF-regulated in our study.

Regarding the other phosphorylation sites that we found to be regulated by TNF- $\alpha$, we decided to look at the functions of the corresponding proteins in an attempt to gain further insight into this group. Interestingly, a number of proteins were found to be implicated in apoptosis. These proteins, listed in Table 4, have been found to play a variety of roles in this cellular process $^{33-38}$. Also, the proteins known function in apoptosis along with information on the corresponding sites and phosphopeptides identified are listed in Table 4. In addition, the majority of these phosphorylation events are novel; except for two: 1.) that of DAP5, which was found in a non-comparative global phosphoproteomic analysis where no mode of regulation was determined 5 and 2.) that of PAK2, where it has been shown to correlate with kinase activation ${ }^{39}$. As previously mentioned, apoptosis can be triggered by TNF- $\alpha$ in some contexts $^{13-15}$; thus, it is not surprising that proteins associated with this cellular process were found to be phosphorylated upon TNF- $\alpha$ treatment. Due to the association of these proteins with apoptosis, one could speculate that these phosphorylation events may regulate the cells decision to undergo apoptosis upon stimulation of the TNF receptor. However, further experiments will be needed to confirm such associations and should be of great interest to those studying this cellular process. 


\section{Conclusion}

In this report we utilize a combination of methods to enhance the detection of phosphorylation sites within a complex protein mixture and apply these methods in a quantitative phosphoproteomic analysis of the TNF pathway. IEF is used in this study to enrich for phosphopeptides within a complex protein digest. A related method has recently been published that exploits the charge state of phosphorylated tryptic peptides in a pre-fractionation step using strong cation exchange resin prior to LC-MS/MS analysis, resulting in the identification of primarily singly phosphorylated peptides 5,6 . In our study however, the prefractionation step via IEF allowed for the collection of multiply phosphorylated tryptic peptides. In the future, it will be of interest to compare the two methods in the ability to efficiently and effectively produce phosphopeptide-enriched fractions from complex protein digests that are representative of the actual phosphopeptide make up of a whole cell protein digest.

Combining a pre-fractionation step prior to IMAC appears to be critical for the overall success in the enrichment of phosphopeptides from a complex peptide mixture, a process of which is fraught with problems of "non-specific" binding of certain classes of unmodified peptides 40 . In addition to our study, similar phosphoproteomic studies have used pre-fractionation prior to IMAC in order to increase the specificity for phosphopeptide enrichment by IMAC ${ }^{6}, 41$. In one of these studies, high-resolution SCX chromatography was used as the pre-fractionation step prior to IMAC ${ }^{6}$. Regarding this use of a high-resolution pre-fractionation step, it would be interesting to compare the low-resolution IEF fractionation method used here to those that can achieve a higher resolution, such as ones recently published ${ }^{42,43}$, and determine if a higher portion of a whole cell protein digest could be used in the IMAC fractionation step without detrimentally increasing the percentage of co-purifying unmodified peptides.

One obvious weakness in our quantitative analysis was the large discrepancy between the number of phosphopeptides identified and the number that could be quantified. The biggest factor contributing to this is the low signal to noise of many of the phosphopeptides observed in the full mass scan (MS spectra). One way that this could be improved is by the use of a hybrid mass spectrometer where time-expensive signal averaging of precursor ion MS spectra can be carried out in parallel with the acquisition of MS/MS spectra, as has been previously done $^{6}$. Such a strategy should result in better signal to noise ratios within MS spectra ultimately improving quantitation, and thus we will explore the usefulness of such a strategy in the near future.

\section{Supplementary Material}

Refer to Web version on PubMed Central for supplementary material.

\section{Acknowledgments}

Thanks to Kumar Bala of Invitrogen for kindly providing the ZOOM IEF Fractionator, Jeff Johnson for programming help, Christian Ruse for thoughtful recommendations, Emily Chen for careful review of the manuscript, and additional members of the Yates lab for helpful discussions. This work was supported by NIH grants RR11823-09, EY13288, and MH067880. G.T.C. and J.D.V. are supported by NIH National Research Service Award fellowships.

\section{References}

1. Hunter T. Cell 2000;100:113-127. [PubMed: 10647936]

2. Yates JR 3rd, Eng JK, McCormack AL, Schieltz D. Anal Chem 1995;67:1426-1436. [PubMed: 7741214] 
3. Mann M, Ong SE, Gronborg M, Steen H, Jensen ON, Pandey A. Trends Biotechnol 2002;20:261-268. [PubMed: 12007495]

4. Ficarro SB, McCleland ML, Stukenberg PT, Burke DJ, Ross MM, Shabanowitz J, Hunt DF, White FM. Nat Biotechnol 2002;20:301-305. [PubMed: 11875433]

5. Beausoleil SA, Jedrychowski M, Schwartz D, Elias JE, Villen J, Li J, Cohn MA, Cantley LC, Gygi SP. Proc Natl Acad Sci U S A 2004;101:12130-12135. [PubMed: 15302935]

6. Gruhler A, Olsen JV, Mohammed S, Mortensen P, Faergeman NJ, Mann M, Jensen ON. Mol Cell Proteomics 2005;4:310-327. [PubMed: 15665377]

7. Annan RS, Huddleston MJ, Verma R, Deshaies RJ, Carr SA. Anal Chem 2001;73:393-404. [PubMed: 11217738]

8. McLachlin DT, Chait BT. Curr Opin Chem Biol 2001;5:591-602. [PubMed: 11578935]

9. DeGnore JP, Qin J. J Am Soc Mass Spectrom 1998;9:1175-1188. [PubMed: 9794085]

10. Syka JE, Coon JJ, Schroeder MJ, Shabanowitz J, Hunt DF. Proc Natl Acad Sci U S A 2004;101:95289533. [PubMed: 15210983]

11. Peters EC, Brock A, Ficarro SB. Mini Rev Med Chem 2004;4:313-324. [PubMed: 15032677]

12. Loyet KM, Stults JT, Arnott D. Mol Cell Proteomics 2005;4:235-245. [PubMed: 15640519]

13. DiDonato JA, Hayakawa M, Rothwarf DM, Zandi E, Karin M. Nature 1997;388:548-554. [PubMed: 9252186]

14. Van Antwerp DJ, Martin SJ, Kafri T, Green DR, Verma IM. Science 1996;274:787-789. [PubMed: 8864120]

15. Chen G, Goeddel DV. Science 2002;296:1634-1635. [PubMed: 12040173]

16. Mercurio F, Murray BW, Shevchenko A, Bennett BL, Young DB, Li JW, Pascual G, Motiwala A, Zhu H, Mann M, Manning AM. Mol Cell Biol 1999;19:1526-1538. [PubMed: 9891086]

17. McDonald WH, Ohi R, Miyamoto DT, Mitchison TJ, Yates JR 3rd. Int J Mass Spec 2002;219:245251.

18. Washburn MP, Wolters D, Yates JR 3rd. Nat Biotechnol 2001;19:242-247. [PubMed: 11231557]

19. Eng JK, McCormack AL, Yates JR 3rd. J Am Soc Mass Spectrom 1994;5:976-989.

20. Tabb DL, McDonald WH, Yates JR 3rd. J Proteome Res 2002;1:21-26. [PubMed: 12643522]

21. Bern M, Goldberg D, McDonald WH, Yates JR 3rd. Bioinformatics 2004;20:I49-I54. [PubMed: 15262780]

22. MacCoss MJ, Wu CC, Liu H, Sadygov R, Yates JR 3rd. Anal Chem 2003;75:6912-6921. [PubMed: 14670053]

23. Zuo X, Speicher DW. Anal Biochem 2000;284:266-278. [PubMed: 10964409]

24. Halligan BD, Ruotti V, Jin W, Laffoon S, Twigger SN, Dratz EA. Nucleic Acids Res 2004;32:W638W644. [PubMed: 15215467]

25. Cauthron RD, Carter KB, Liauw S, Steinberg RA. Mol Cell Biol 1998;18:1416-1423. [PubMed: 9488457]

26. Butt E, Immler D, Meyer HE, Kotlyarov A, Laass K, Gaestel M. J Biol Chem 2001;276:7108-7113. [PubMed: 11383510]

27. Varticovski L, Chahwala SB, Whitman M, Cantley L, Schindler D, Chow EP, Sinclair LK, Pepinsky RB. Biochemistry 1988;27:3682-3690. [PubMed: 2457390]

28. Bruce JI, Yule DI, Shuttleworth TJ. J Biol Chem 2002;277:48172-48181. [PubMed: 12368283]

29. Zhong H, SuYang H, Erdjument-Bromage H, Tempst P, Ghosh S. Cell 1997;89:413-424. [PubMed: 9150141]

30. Hayden MS, Ghosh S. Genes Dev 2004;18:2195-2224. [PubMed: 15371334]

31. Piller V, Piller F, Fukuda M. J Biol Chem 1989;264:18824-18831. [PubMed: 2530225]

32. Woo MS, Ohta Y, Rabinovitz I, Stossel TP, Blenis J. Mol Cell Biol 2004;24:3025-3035. [PubMed: 15024089]

33. Deiss LP, Feinstein E, Berissi H, Cohen O, Kimchi A. Genes Dev 1995;9:15-30. [PubMed: 7828849]

34. Kasof GM, Goyal L, White E. Mol Cell Biol 1999;19:4390-4404. [PubMed: 10330179]

35. Boyd JM, Malstrom S, Subramanian T, Venkatesh LK, Schaeper U, Elangovan B, D'Sa-Eipper C, Chinnadurai G. Cell 1994;79:341-351. [PubMed: 7954800] 
36. Bokoch GM. Cell Death Differ 1998;5:637-645. [PubMed: 10200518]

37. Henis-Korenblit S, Shani G, Sines T, Marash L, Shohat G, Kimchi A. Proc Natl Acad Sci U S A 2002;99:5400-5405. [PubMed: 11943866]

38. McCarthy JV, Ni J, Dixit VM. J Biol Chem 1998;273:16968-16975. [PubMed: 9642260]

39. Gatti A, Huang Z, Tuazon PT, Traugh JA. J Biol Chem 1999;274:8022-8028. [PubMed: 10075701]

40. Posewitz MC, Tempst P. Anal Chem 1999;71:2883-2892. [PubMed: 10424175]

41. Nuhse TS, Stensballe A, Jensen ON, Peck SC. Mol Cell Proteomics 2003;2:1234-1243. [PubMed: 14506206]

42. Essader AS, Cargile BJ, Bundy JL, Stephenson JL Jr. Proteomics 2005;5:24-34. [PubMed: 15672457]

43. Moritz RL, Ji H, Schutz F, Connolly LM, Kapp EA, Speed TP, Simpson RJ. Anal Chem 2004;76:4811-4824. [PubMed: 15307793] 


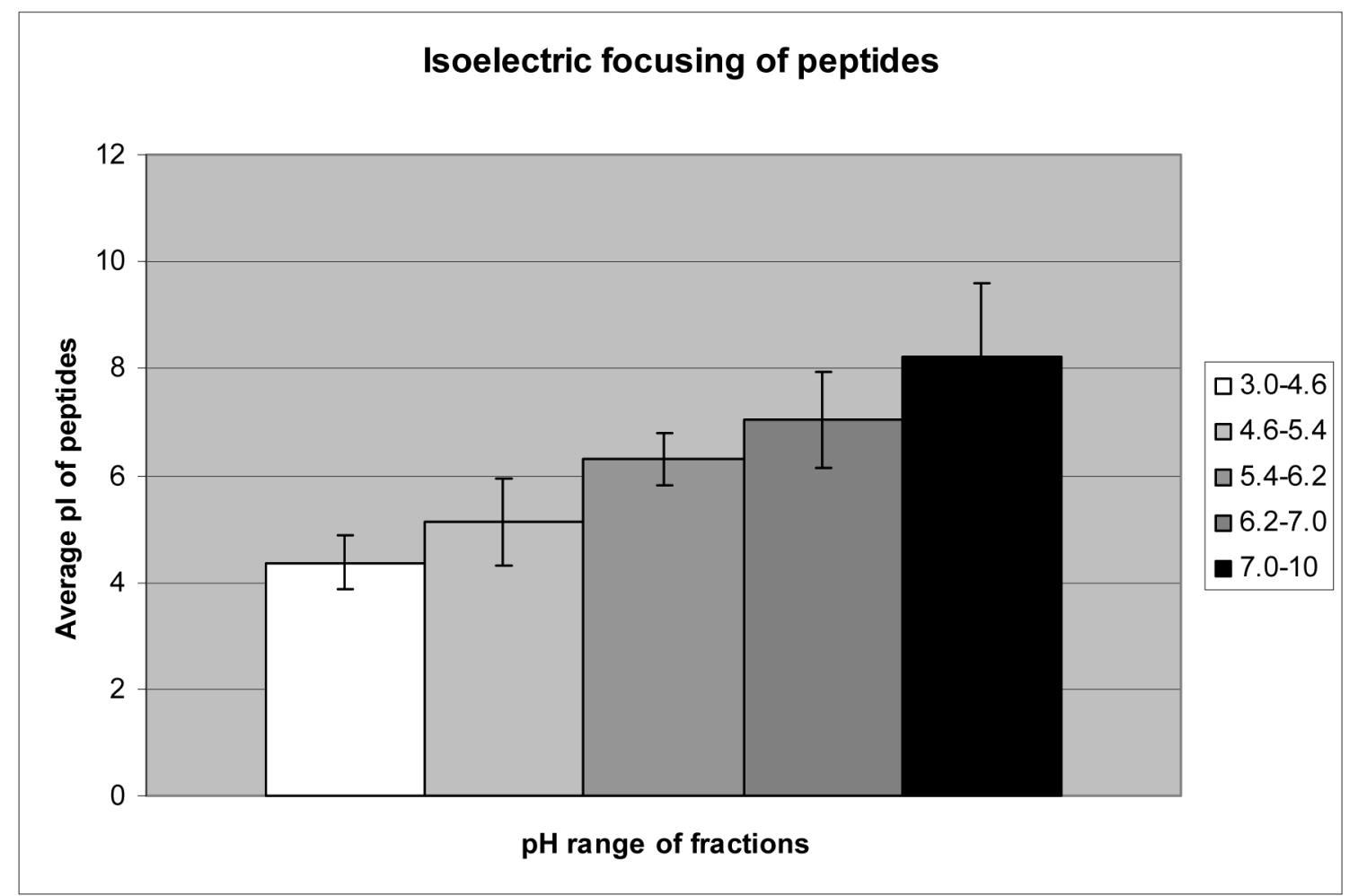

Figure 1. Isoelectric focusing of trypsin-digested whole cell protein extract

HeLa cell protein extract was digested with trypsin and subjected to prefractionation via IEF prior to MudPIT analysis. For the unmodified peptides identified (see text for criteria), the pI of each was determined and the average for each IEF fraction is displayed. 


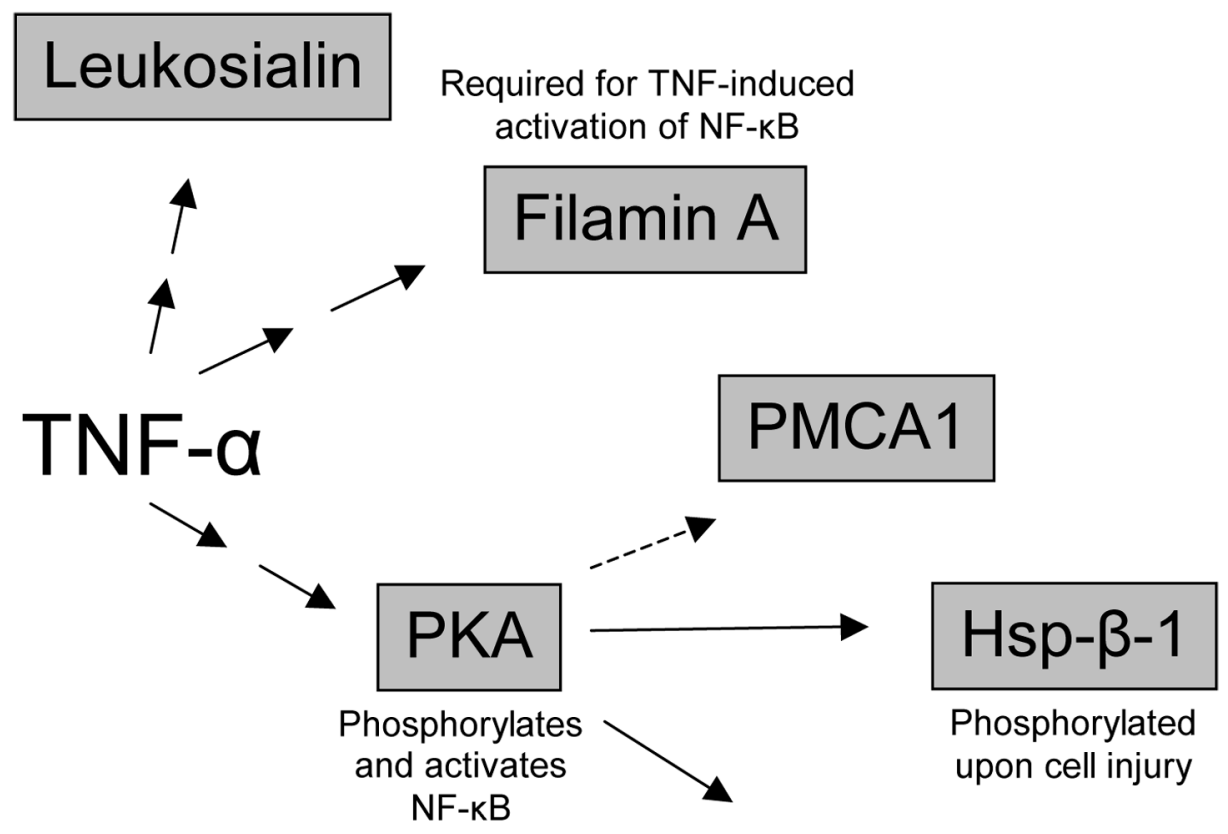

\section{Annexin 1}

Figure 2. Up-regulated phosphorylation events found that have been previously linked to the TNFa pathway

The proteins boxed in grey were found to be phosphorylated in a TNF- $\alpha$-dependent manner. Found were a kinase-activating phosphorylation on PKA-c- $\alpha$ and previously known PKAdependent phosphorylation sites found on annexin 1 , Hsp- $\beta-1$, and one possible PKA site on PMCA1 (see text). Other findings included sites on leukosialin and filamin A. All

phosphorylation events have been directly or indirectly implicated in the TNF- $\alpha$ pathway, and some of the proteins have been implicated in additional activities associated with the action of TNF- $\alpha$. 
Table 1

IEF of digested whole cell protein extract, comparisons of unmodified (unmod.) and phosphorylated (phos.) peptides identified in each fraction by MudPIT.

\begin{tabular}{lccc}
\hline IEF fractions & unmod. peptides & phos. peptides \\
\hline pH 3 & & phos./unmod. \\
pH 4.6 & 555 & 12 & 13 \\
pH 5.4 & 592 & 13 & 1.00 \\
pH 6.2 & 1867 & 5 & 0.32 \\
pH 7 & 1445 & 41 \\
\hline Non-redundant Total & 1350 & 0.00 \\
\hline
\end{tabular}

* Ratio of the number of identified peptides normalized to fraction $\mathrm{pH} 3$. 
Table 2

IEF of whole cell protein extract, comparisons of unmodified and phosphorylated peptides and corresponding proteins identified in each fraction by MudPIT.

\begin{tabular}{lccc}
\hline IEF fractions & proteins & unmod. peptides & phos. peptides \\
\hline pH 3 & 388 & 801 & 3 \\
pH 4.6 & 327 & 811 & 1 \\
pH 5.4 & 403 & 1241 & 5 \\
pH 6.2 & 566 & 1723 & 8 \\
pH 7 & 516 & 1085 & 23 \\
\hline Non-redundant Total & 1714 & 5435 & \\
\hline
\end{tabular}


Table 3

TNF-up-regulated sites found that have been previously linked to the pathway.

\begin{tabular}{|c|c|c|c|c|}
\hline & IPI \# & $\begin{array}{l}\text { Fold abundance } \\
\text { increase upon } \\
\text { TNF-stimulation }\end{array}$ & $\begin{array}{l}\text { Qualitatively } \\
\text { determined to be } \\
\text { upregulated }\end{array}$ & $\operatorname{Site}(\mathbf{s})^{* * *}$ \\
\hline Leukosialin & IPI00027430.1 & 5.9 & & $\mathrm{~S} 351, \mathrm{~S} 363, \mathrm{~S} 368$ \\
\hline \multirow[t]{2}{*}{$\begin{array}{l}\text { Heat-shock protein beta-1 } \\
(\text { Hsp- } \beta-1)\end{array}$} & IPI00025512.2 & 2.9 & & $\mathrm{~S} 15$ \\
\hline & & 2.5 & & $\mathrm{~S} 82$ \\
\hline Annexin 1 & IPI00218918.3 & 6.5 & & Т216, Т223, Т226/Т227 \\
\hline Filamin A & IPI00302592.1 & & 2 & S2156 \\
\hline $\begin{array}{l}\text { Plasma membrane } \\
\text { calcium-transporting } \\
\text { ATPase } 1 \text { (PMCA1) }\end{array}$ & IPI00021695.1 & & 3 & S1193 \\
\hline $\begin{array}{l}\text { cAMP-dependent protein } \\
\text { kinase, alpha-catalytic } \\
\text { subunit (PKA-c- } \alpha \text { ) }\end{array}$ & IPI00217960.1 & & 3 & T190/T188 \\
\hline \multicolumn{5}{|l|}{ * Determined by RelEx } \\
\hline \multicolumn{5}{|c|}{$\begin{array}{l}\text { This is the number of times each phosphopeptide was identified in the } 3 \text { replicate runs, each is on the qualitatively-determined TNF-regulated list } \\
\text { described in the text. }\end{array}$} \\
\hline
\end{tabular}




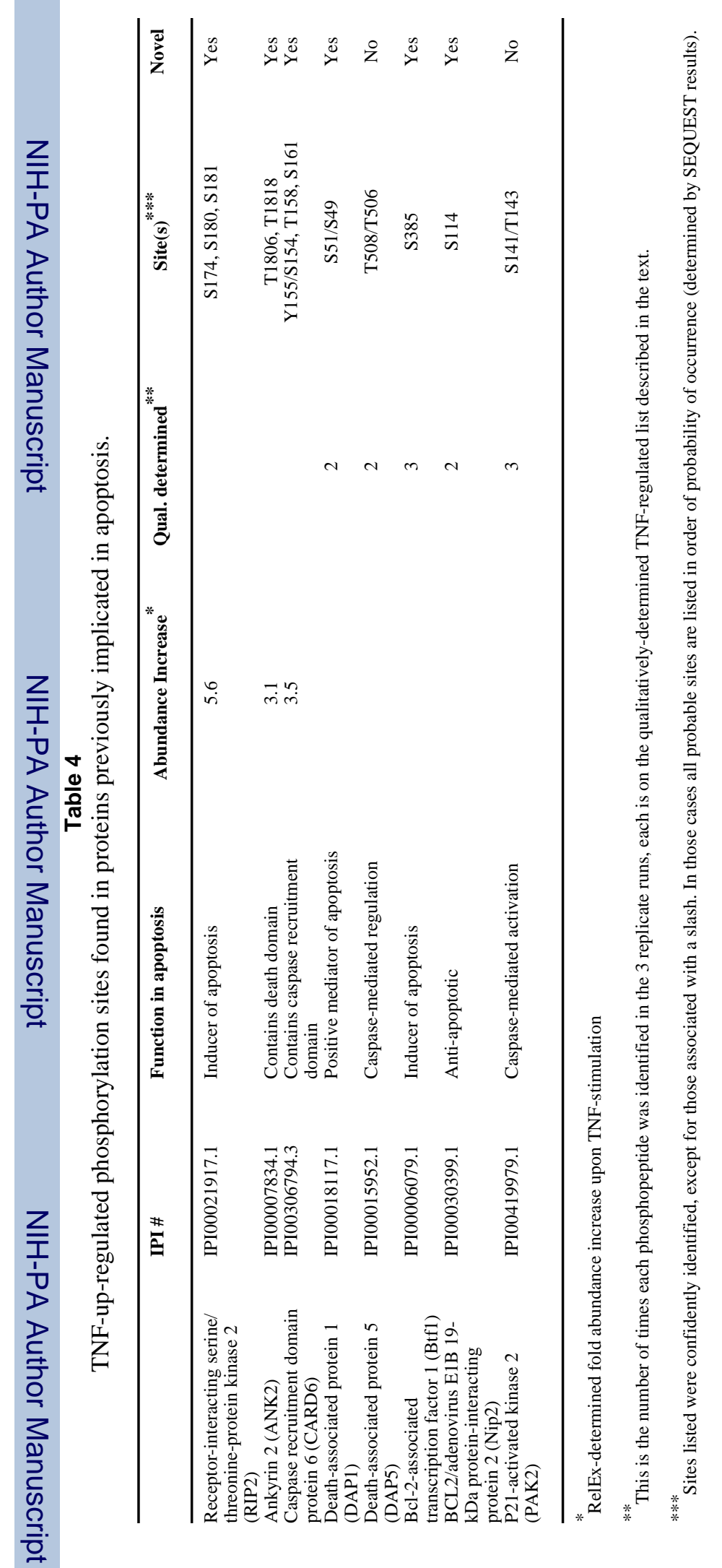

J Proteome Res. Author manuscript; available in PMC 2008 October 20. 